\title{
Pathophysiology of the Human His-Purkinje \\ System
}

Editor

MASOOD AKHTAR

\section{CARDIAC \\ ELECTROPHYSIOLOGY CLINICS}

www.cardiacEP.theclinics.com

Consulting Editors

RANJAN K. THAKUR

ANDREA NATALE

December 2016 • Volume 8 • Number 4 